\title{
SEXUALIDADE DE UNIVERSITÁRIAS: VIVÊNCIAS E DESEMPENHO DE PAPEIS NO CONTEXTO FAMILIAR E FORA DELE.
}

Adriele Cristine de Freitas Batista, Maísa Gonçalves Lima, Raul Aragão Martins.

Universidade Estadual Paulista - UNESP, Programa de Pós-Graduação Ensino e Processos Formativos, São José do Rio Preto, SP. Email: adrielecfb@hotmail.com. Agência de fomento: PIBIC/CNPq

\begin{abstract}
RESUMO
A iniciação sexual dos jovens e adolescentes está permeada de tabus e inseguranças. $O$ contexto moderno atual apresenta novas formas de obter informação através dos meios de comunicação e das redes sociais. Pesquisas apontam que nessa nova fase, além das fontes proporcionadas pelas tecnologias, as amizades assumem papel importante, não somente para obtenção de informação, mas também como ambiente social de aceitação. Diante desse quadro o objetivo deste trabalho foi verificar como as universitárias se posicionam a respeito da sexualidade no ambiente familiar e também com seus pares e para isso utiliza-se os dados levantados em uma pesquisa de cunho qualitativo. Participaram da pesquisa alunas da área de humanidades de uma universidade pública, campus situado em São José do Rio Preto, que responderam a um questionário com perguntas fechadas e abertas. Espera-se que o conhecimento oriundo deste estudo venha a colaborar na elaboração de programas de educação sexual.
\end{abstract}

Palavras-chave: Sexualidade, Universitárias, Família.

\section{THE SOCIAL ROLE ABOUT SEXUALITY PERFORMED BY FEMALE COLLEGE ESTUDENTS WITHIN AND OUTSIDE THE FAMILY ENVIRONMENT.}

\begin{abstract}
Sexual initiation of young people and adolescents is permeated by taboos and insecurities. The current modern context presents new ways of obtaining information through the media and social networks. Researches point out that in this new phase, besides the sources provided by the technologies, the friendships play an important role, not only to obtain information, but also as a social environment of acceptance. In view of this framework, the objective of this study was to verify how female college students position themselves regarding sexuality in the family environment and also with their peers and for this the data collected in a qualitative research is used. Students from the humanities area of a public university, campus located in São José do Rio Preto, participated in the survey, who answered a questionnaire with closed and open questions. It is hoped that the knowledge coming from this study will collaborate in the elaboration of sexual education programs.
\end{abstract}

Keywords: Sexuality, Female College Studente, Family. 


\section{INTRODUÇÃO}

A sexualidade humana, enquanto construção social e histórica é influenciada por fatores sociais, culturais e políticos. Esta afirmação se confirma ao observarmos que no decorrer da história da humanidade a vivência deste aspecto por homens e mulheres aconteceu de distintas formas. Alguns marcos históricos foram de extrema importância neste processo, como por exemplo, o surgimento da pílula anticoncepcional na década de 1960. Apesar das mudanças caminharem para uma maior libertação da sexualidade, é importante apontar que esta abertura acontece de maneira diferente para os dois sexos, sendo que a sexualidade feminina continua sendo alvo de recriminações.

Tendo sua sexualidade castrada desde a infância, quando atingem a maturidade sexual, as mulheres possuem seus direitos sexuais e reprodutivos violados pelas relações de poder existentes entre os gêneros, em que é esperada uma postura comportada como reflexo de uma "mulher de respeito". Neste contexto, cabe a elas negociar o preservativo, caso contrário, serão responsabilizadas pela gravidez não planejada (RAMOS, 2015). A prática sexual é permitida dentro do relacionamento fixo, mas deve ser mantida em sigilo, para que seja preservada a integridade moral da mulher. Esses valores são socializados e reforçados por diversas instituições e refletem diretamente no exercício da sexualidade das jovens e adolescentes, que acabam limitando suas vivências ao prazer do outro como forma de garantir respeito.

É, a princípio, no âmbito familiar que o indivíduo apreende as primeiras normas socialmente construídas, que orientarão sua sexualidade. A família tida como um microssistema, é influenciada, mas também influencia um sistema social amplo. Ela apresenta-se como primeira instituição de interação do indivíduo em desenvolvimento (MONTALVÃO; COSTA, 2009) e, portanto, ostenta influências sob as crenças, comportamentos e valores que orientarão os pensamentos e ações dos indivíduos inseridos neste contexto (BALTOR, 2014).

Ressel (2011), em pesquisa com adolescente, aponta que apesar de atualmente o tema da sexualidade ser conduzido com maior transparência dento do ambiente familiar, muitas vezes este ainda carrega resquícios culturais da repressão. Esse mesmo estudo evidencia que quando a família assume o papel de orientar as meninas sobre o uso do preservativo, esta é realizada pela mãe e o discurso segue o padrão de prevenção à gravidez, sem mencionar doenças, ou qualquer outro aspecto relacionado com a sexualidade em geral, como o prazer resultante dessa prática. Apesar deste quadro, o padrão entre as famílias é manter o assunto de maneira velada, sendo que em sua maioria, as famílias nem mesmo conversam abertamente sobre sexualidade, recaindo desta forma sob outros grupos o papel de acolher e orientar as dúvidas e anseios a respeito deste tema. Neste sentido, Borges, Nichiata e Schor (2006), em pesquisa com adolescentes, mostram que estes, em sua maioria, obtêm informação sobre sexualidade prioritariamente com amigos, recorrendo à família e à escola somente quando buscam informação sobre doenças e gravidez.

O relacionamento entre grupos de iguais, como apontam Taquette e Vilhena (2008), simboliza o modelo e a proteção substituta à família. Os jovens, ao buscar por sua identidade e autonomia, dão voz e fazem ser ouvidos por aqueles que compartilham das mesmas experiências, medos, e angústias. Entende-se que o relacionamento do grupo de iguais se configura como "mais aberto" na medida em que aceitam e acolhem a sexualidade como natural, diferentemente da família e da escola.

É nesse contexto que surge o interesse em investigar o modo com as jovens universitárias vivenciam e desempenham papeis a respeito da sexualidade no contexto familiar e fora dele. Para tanto, foram utilizados dados obtidos a partir de uma pesquisa desenvolvida nos anos de 2016 e 2017 em um campus universitário situado na cidade de São José do Rio Preto - SP. 


\section{METODOLOGIA}

A pesquisa desenvolvida é de cunho qualitativo e foi aprovada pelo comitê de ética (CAAE: 57016016.9.0000.5466). O levantamento dos dados ocorreu a partir da aplicação de questionários às alunas de 10 e 4 을 ano dos cursos de Letras e Pedagogia de uma universidade pública. Os questionários foram estruturados em duas partes, sendo a primeira de questões fechadas com o objetivo de criar uma caracterização das participantes e a segunda com 12 questões abertas. A amostra coletada constou de 68 questionários aplicados, que foram inicialmente digitalizados, seguido de um agrupamento das informações por questão, desta forma, a partir de cada questão foi possível levantar categorias que facilitaram a análise da questão (BOGDAN e BIKLEN, 1994). O número de categorias variou de acordo com a questão em detrimento do assunto abordado.

\section{RESULTADOS}

Das 68 estudantes que participaram do estudo 52,9\% estavam no primeiro ano. A idade das participantes variou entre 18 e 36 anos, sendo que a média das alunas do curso de letras foi de 21,17 anos e do curso de pedagogia, 22,18 anos.

Com relação ao local de moradia as estudantes declararam residir com a família, resultando em $86,8 \%$ do total de participantes. Como apresenta Brandão (2004) esta é uma característica da sociedade atual em que ocorre um descompasso entre autonomia e dependência, pois com o prolongamento dos estudos há uma maior dificuldade em conquistar independência, especialmente a financeira.

A respeito da educação sexual, os dados nos mostram que esta aconteceu prioritariamente no âmbito familiar, representando um total de $46 \%$, seguido da escola, com $28,6 \%$. Também foram apontados como importantes na educação sexual os grupos de amigos (15,9\%). Notamos que a mídia, diferentemente do que ocorre em pesquisas realizadas com adolescentes de camadas populares, é o mecanismo que menos influencia na educação sexual das jovens que participaram desta pesquisa.

Em relação ao início de vida sexual 55,9\% delas declararam que já tiveram sua primeira relação, mas existe uma diferença significante por cursos entre elas, pois somente $28,9 \%$ das alunas de letras são ativas sexualmente $\left(\chi^{2}=8,040, p=0,005\right)$. Em contrapartida entre as alunas de pedagogia este dado é de $71,1 \%$. Esta discrepância nos percentuais pode ser interpretada devido a maior abertura dentro do curso de pedagogia para discussão de temas relacionados à sexualidade, enquanto no curso de letras há um maior interesse na discussão dos conteúdos científicos sistematizados, ocupando a temática sexualidade, bem como os demais temas transversais, um lugar secundário.

A idade média da primeira relação sexual das 38 estudantes que declararam ser ativas sexualmente é de 17,29 anos, não havendo disparidade significativa entre as alunas dos dois cursos. Este início da vida sexual mais tardia, comparado à média nacional que é em torno dos 15 anos, sendo que as mulheres se iniciam mais tardiamente que os homens (BRASIL, 2006; HUGO et al, 2011), pode ser interpretado pela constatação de diversos autores como Santos; Abud; Inagaki (2009) e Donati e Martins (2015) de que a maior escolaridade parece contribuir para um início mais tardio da vida sexual, além deste fator, outros aspectos como raça, grupo social, idade do primeiro emprego, do primeiro namoro, entre outros (HEILBORN et al , 2006), também interferem no protelação da atividade sexual.

No tocante ao tipo de relacionamento, podemos notar um grupo predominantemente de participantes que declaram estar em um relacionamento fixo, caracterizado como namoro, este dado representa $47,7 \%$ e é seguido pelo percentual de participantes solteiras, que representa $43,1 \%$. Após a caracterização das participantes dessa pesquisa, foram feitas perguntas abertas sobre a temática a fim de identificar o modo como as universitárias desempenham seus papeis sexuais no contexto familiar e fora dele. 
A partir da questão "Como você entende a sexualidade?" percebemos que majoritariamente (32,4\%), compreendem a sexualidade enquanto sinônimo de prática sexual, este dado revela os efeitos de uma educação escolar e também familiar que considera a sexualidade somente a partir dos aspectos biológicos que focalizam os órgãos reprodutores e as medidas preventivas.

"Entendo que a sexualidade é um ato importante, pois ao fazê-lo a pessoa precisa estar ciente de quais consequências a sexualidade pode trazer ou não."

"Para mim, sexualidade tem haver com a vida sexual e os órgãos sexuais e as coisas que são relacionadas tipo câncer de próstata ou de mama."

Seguida da "prática sexual", aparece a categoria "natural" (30,9\%), que assim como a anterior, apresenta-se como herança da educação sexual, já que considera a sexualidade enquanto um aspecto natural, inato ao ser humano, relacionada à função de reprodução, desconsiderando os aspectos sociais e culturais presentes na construção da sexualidade. A categoria "complexidade" aparece em $10,3 \%$ das respostas e indica uma compressão da sexualidade que reconhece a amplitude do tema, considerando todos os aspectos a ele relacionados. Além destas, a categoria "não quero falar", que apareceu com uma frequência de $7,4 \%$, nos apresenta a sexualidade sob o olhar da repressão, pois indica este tema como íntimo, secreto, privado.

"Algo íntimo, e deve ser preservado, pois pertence a cada um."

"Entendo a sexualidade como uma coisa muito íntima e pessoal, porém cada qual lida com ela da maneira que quer."

A respeito do questionamento "Dentro do ambiente familiar você possui abertura para diálogo sobre o tema da sexualidade? Especifique essa abertura", 67,6\% das participantes afirmaram possuir abertura para diálogo dentro da família. Dentre elas, $50 \%$ afirmaram possuir um diálogo aberto, podendo tratar de qualquer assunto, 8,8\% afirmaram possuir um diálogo restrito à prevenção, enquanto $7,4 \%$ preferem não falar, apesar da abertura.

Ao encontro da questão apresentada, questionamos então "Qual a sua postura dentro do ambiente familiar com relação à sexualidade?". As respostas a esta pergunta geraram três categorias, sendo que a que possuiu o maior percentual, com 30 respostas $(44,1 \%)$ foi não converso. A partir desses dados podemos perceber a contradição na fala das participantes que inicialmente assumem a existência de um diálogo, caracterizando-o como aberto e em seguida se contradizem ao assumir a inexistência dele. Podemos afirmar que a dificuldade em ter uma postura onde haja um diálogo aberto sobre sexualidade se dá pelo fato do assunto causar constrangimento à família, que vulgariza e instiga preconceitos de inúmeras ordens.

"Tento manter o respeito para com minha família para não expor ela em nenhuma situação constrangedora. Sou reservada."

"A minha postura em relação ao assunto é fechada, pois ao descobrirem a minha sexualidade, houve conflitos em toda a familia."

A questão "Com quem você conversa sobre sua sexualidade?", gerou cinco categorias, sendo indicadas na maioria das respostas mais de uma categoria. Os amigos aparecem em 54 questionários, enquanto a família apareceu em 34 respostas, seguida do namorado, que foi indicado em 20 questionários. Cinco participantes indicaram conversar sobre o assunto com outros, como o ginecologista, conhecidos da internet, ou qualquer pessoa que queira falar sobre o 
tema, e duas alunas indicaram não conversar com ninguém. As respostas desta questão nos comprovam o que foi apontado por Dias, Matos e Gonçalves (2007, p.629) de que

[...] A maioria dos jovens considera os pares como uma fonte confortável e bastante acessível de informação e de suporte, permitindo-lhes sentiremse mais à vontade para trocar ideias, ouvir conselhos e opiniões e esclarecer dúvidas.

E também por Pereira (1993), de que apesar de existir a procura por outros meios de obter informação, é unânime a procura pelo grupo de pares para função.

\section{DISCUSSÃO}

Observou-se a partir dos dados coletados que as universitárias possuem um ideal familiar, como apresentado por Montalvão e Costa (2009), mesmo com o crescente número de famílias monoparentais e também com outras formas de organização, não se excluiu por completo o valor atribuído à família nuclear, constituindo esta, ainda hoje, como o modelo hegemônico, como relata Carvalho (2003, apud CARDOSO; FÉRES-CARNEIRO, 2008, p. 524)

[...] família está impregnada de idealizações no imaginário coletivo, descrevendo as seguintes expectativas em relação a ela: configuração segundo o modelo de família nuclear burguesa; promoção de cuidados, proteção, aprendizagem de afetos e de melhoria na qualidade de vida de seus membros; construção de vínculos e relacionamentos de pertencimento e de inserção social na comunidade mais ampla.

Observamos esta característica através da afirmação pelas participantes da pesquisa sobre a existência de um diálogo aberto com seus familiares a respeito de sua sexualidade. Como evidenciado esta afirmação pode ser interpretada como uma busca em manter o ideário de família nuclear burguesa, visto que elas mostram em outros momentos que na realidade mantém-se afastadas da discussão de tal assunto, com receio de constranger os familiares.

As análises também evidenciaram o relacionamento com o grupo de pares como a maior fonte de informação. Ao comparar as respostas a respeito de como é o diálogo nos grupos de amigos, a maioria das respostas indicam conversas divertidas, ambiente de acolhimento, enquanto dentro do ambiente familiar estas são restritas a especificações que indicam a abertura, sem detalhes de como este ocorre. Isso se deve ao fato de que educação sexual recebida dentro das famílias não contemplaram a sexualidade como parte integrante do ser humano, apenas relacionada aos aspectos preventivos.

\section{CONCLUSÃO}

Este contexto dual vivenciado pelas participantes reforça a importância em discutir amplamente a sexualidade nos diferentes espaços de socialização. Justifica-se essa necessidade a partir do entendimento de que quando há repressão de um determinado comportamento, dentro de algum espaço, como, por exemplo, na família, ele se torna um lugar de distância e silenciamento entre os sujeitos envolvidos, fato este que não ocorre entre os pares, pois o acolhimento proporcionado pelo grupo permite que eles compreendam e naturalizem a sexualidade como qualquer outra situação que possa ser apreciada sem que haja recriminação.

É importante ressaltar que a experiência vivenciada e compartilhada entre os pares contribui grandiosamente no processo de amadurecimento, no entanto, elas não são suficientes quando há a pretensão de compreender a sexualidade em sua amplitude. Desse modo, emerge a necessidade da abertura para o diálogo a respeito da sexualidade nos diferentes espaços de 
formação de maneira a não estigmatizar a temática, mas valorizar os aspectos identitários do indivíduo e reforçar os aspectos preventivos a ela.

Sendo assim, enfatizamos a educação sexual enquanto uma ferramenta importantíssima de libertação sexual e (re)conhecimento do próprio eu e do corpo, de modo a desnaturalizar as prescrições sobre a sexualidade e assim desfrutarem-na plenamente.

\section{REFERÊNCIAS}

BALTOR, Marja Rany Rigotti et al. O texto em seu contexto: o que é família para você?. Rev. pesqui. cuid. fundam. (Online); 6(1): 293-304, jan.-mar. 2014.

BOGDAN, R. C.; BIKLEN, S. K. Investigação qualitativa em educação. Porto, Porto Editora, 1994.

BORGES, Ana Luiza Vilela; NICHIATA, Lúcia Yasuko Izumi; SCHOR, Néia. Conversando sobre sexo: a rede sociofamiliar como base de promoção da saúde sexual e reprodutiva de adolescentes. Rev. Latino-Am. Enfermagem, Ribeirão Preto, v. 14, n. 3, p. 422-427, jun. 2006.

BRANDÃO, E. R. Iniciação sexual e afetiva: exercício da autonomia juvenil. In: HEILBORN, M. L. (Org). Família e Sexualidade. Editora FGV. Rio de Janeiro, 2004.

BRASIL. Ministério da Saúde. Secretaria de Vigilância em Saúde. Programa Nacional de DST e Aids. Diretrizes para implantação do Projeto Saúde e Prevenção nas Escolas / Ministério da Saúde, Secretaria de Vigilância em Saúde. - Brasília : Ministério da Saúde, 2006. 24 p. - (Série A. Normas e Manuais Técnicos).

CARDOSO, C.L.; FÉRES-FÉRES-CARNEIRO, T.F. Sobre a família: Com a palavra, a comunidade. Revista Estudos e Pesquisas em Psicologia, Rio de Janeiro, V. 8, n. 2, p. 523-539, $1^{\circ}$ semestre de 2008.

DIAS, S.; MATOS, M.G.; GONÇALVES, A. Percepção dos adolescentes acerca da influência dos pais e pares nos seus comportamentos sexuais. Análise Psicológica. 2007;4(XXV):625-34.

DONATI, Fabiana A., MARTINS, Raul A. Juventude e conduta sexual: a formação da mulher jovem para a vida sexual. In: Raul A. Martins e Luciana Ap. N. da Cruz. Desenvolvimento sócio moral e condutas de risco em adolescentes. Campinas, SP : Mercado de Letras, 2015, p.117-42.

HEILBORN ML. et al (Orgs). O aprendizado da sexualidade: reprodução e trajetórias sociais de jovens brasileiros. Rio de Janeiro: Editora Garamond/Editora Fiocruz; 2006.

HUGO, T. D. O. et al. Fatores associados à idade da primeira relação sexual em jovens: estudo de base populacional. Cad. Saúde Pública, Rio de Janeiro, 27(11):2207-2214, nov, 2011.

MONTALVÃO, Thaís Angélica Garcia; COSTA, Nina Rosa do Amaral. A concepção de família na ótica de adolescentes de classe popular. Investigação. v. 9, n. 1, p. 63-72, jan./abr. 2009.

PEREIRA, M. Com quem falam os adolescentes sobre sexualidade? llações como base nos resultados de um questionário. Análise Psicológica, 3, 415-424, 1993. 
RAMOS, Janaine B. Universitárias e a negociação do uso do preservativo com o parceiro: relações de gênero implícitas na sexualidade. [Trabalho de Conclusão de Curso]. São José do Rio Preto: Universidade Estadual Paulista. Curso de Pedagogia. 2015.

RESSEL, Lúcia Beatriz et al . A influência da família na vivência da sexualidade de mulheres adolescentes. Esc. Anna Nery, Rio de Janeiro, v. 15, n. 2, p. 245-250, jun. 2011.

SANTOS, T. L.; ABUD, A. C. F.; INAGAKI, A. D. M. Vulnerabilidade às doenças sexualmente transmissíveis entre mulheres com alta escolaridade. Rev Enferm UERJ, out/dez; 17(4):502-5. 2009.

TAQUETTE, Stella R.; VILHENA, Marília Mello de. Uma contribuição ao entendimento da iniciação sexual feminina na adolescência. Psicol. estud., Maringá , v. 13, n. 1, p. 105-114, Mar. 2008. 